\title{
Understanding Adoption or Resistance of Long-Standing Belief Systems within the Equine Industry
}

By

Robyn Lord, University of South Florida

\begin{abstract}
The equine industry is changing after hun- both sides: natural and traditional. Leaders dreds of years of solid foundations built on long-standing beliefs. The natural horse and hoof faction introduction have spurred a push to wake up this sleeping, yet strong industry. Both factions of the industry--hoof care and horsemanship are affected. The debate of natural versus traditional is growing, causing friction in some areas and asking participants to pick a side.

Long-standing belief systems are embedded both culturally and historically within the equine industry. A new belief system has been introduced into this industry causing friction to the traditional beliefs. The interviews under analysis are in pursuance of uncovering the possible reasons why people are resisting change or adopting a new belief system. were chosen for their role in either inciting adopting or resistance. Also included in the interview process are middle management professionals who are witnessing the friction of new beliefs and the contradictions to the industry status quo. This research was conducted by interviewing 41 leaders within the industry, representing a wide array of disciplines, both natural and traditional. Their viewpoints represent This research was conducted with industry leaders that represent the current state of the industry under analysis.
\end{abstract}

Keywords: Horses, Equine, Natural Horsemanship, Qualitative Data Analysis, NVIVO, Status Quo, Change

Copyright $\odot$ 2019, Robyn Lord. This article is published under a Creative Commons BY-NC license. Permission is granted to copy and distribute this article for non-commercial purposes, in both printed and electronic formats 
The equine industry is currently in a state of debate. The previously unchanged belief system of horses, horsemanship and their welfare stood firm and understood by all involved. With little to no change for hundreds of years, the industry became complacent. It was not a matter of stagnation. The industry seemed to be moving along while underneath, there was a silent rumble amongst its participants. People did not question what was correct or incorrect in the industry from horsemanship to hoof care. The industry experienced innovation in some areas, but that innovation was within the confines of the long-standing belief systems. It became a "this is how it's done" industry, and historically its participants were confident that the proof of success was in the results thus far.

The industry being confident in their research and actions, created a false sense of security, opening the door to easy entrance for new markets. In this research process, it was evident that a change had taken place. Over 20 years ago, the natural horse movement challenged the traditional industry through a new belief system. The upset in the horsemanship area started slowly, but subsequently birthed a new belief system also in hoof care. Natural horsemanship (NH) and hoof care are now an item of debate amongst the industry leaders and the people who pride themselves as members. Practitioners are often evangelical about their methods, portraying $\mathrm{NH}$ as a radical departure from traditional methods. In doing so, they create a clear demarcation from the practices and beliefs of the conventional horse-world (Birke, 2007).

The purpose of this research is to determine what long-standing belief systems exist within the industry, and which of those beliefs have since been radically changed. Belief systems are the stories we tell ourselves to define our personal sense of reality. Every human being has a belief system that they utilize, and it is through this mechanism that we individually "make sense" of the world around us (UsóDoménech \& Nescolarde-Selva, 2016).

The qualitative data that was gathered for this research allows for the synthesis of two well-known adoption models: Kuhn's (1962) theory of paradigm shift and Lewin's (1997) force field analysis. The former model emphasizes the resistance of widely held scientific belief systems to radical change based on new observations, while the latter examines individual resistance to change and hypothesizes the existence of a tipping point at which beliefs will change. Based on the following evidence gathered, the best fit is a hybrid of these two models that is constructed to highlight the macro existence of friction and a micro-examination of adoption or resistance. Research has been conducted that explores the beliefs of expert individuals who represent a wide overview of the industry. The paradigm shift demonstrates a moment in time where momentum begins and awareness of a proposed change to the belief systems is introduced. The micro level of articulation within the industry is shown to demonstrate the probability of adoption or resistance within the friction area. A tipping point model such as force field analysis is a process extension of that moment in time. Qualitative data was collected to elicit change in action or reaction.

\section{Review of Research}

Historically, the nature of change has been studied with such well-known authors such as Peter Drucker, John Kotter, Dan Cohen, and many others. Many topics throughout their research include change initiatives, change processes, and change derailments. Businesses are thriving on traditional beliefs while others are struggling to block adoption of new beliefs. Many adopt new beliefs and are tried and true, while others revert. What are the circumstances around the successful or failed attempts at change?

Many industries rely on modeling the best practices of leaders within the industry to achieve success. The study of strategic designs as with General Motors has been the blueprint for change management. It is usual to study those who are successful. Industry leaders thrive on innovation and the ownership of driving those decisions weighs heavily on the understanding of the acceptance of change. It was stated that $75 \%$ of organizational change programs fail (Bremer, 2012). In a recent 2017 research study from McKinsey and Company, that number decreased to $70 \%$ (Gleeson, 2017). The hypothesis to this would be that the area of change management is being flooded with great research and intuitive understanding of change criteria. The implementation failure rate of organizational change remains high and one of the most common causes of this is the resistance to change. Although the resistance to change is considered a natural reaction, it is necessary to understand the causes and identify the measures for its reduction (Stegaroiu \& Talmaciu, 2016).

To contribute to this realm, this qualitative research searches into a division of human behavior built around long-standing belief systems. The definition being used for a long-standing belief system in the context of the equine industry is a belief that is held through generational inheritance of cultural beliefs and understandings that are neither questioned nor 
radically changed over time. The equine industry is unique in that the beliefs being held are status quo and strongly embedded into horsemanship culture. Change being difficult and sometimes short-lived within an industry is not the case for the equine industry. The change within the industry has rewritten the history books and the understanding of horses and horsemanship. To the industry, this is not a surface level change. This represents a change that in some cases has become a lifestyle and a cultural change in mindset. Understanding how this disruption and possible future paradigm shift occurred could be extremely beneficial to the research of change management.

\section{Interviewees' Backgrounds}

The interviewees span many facets of the equine industry. Forty-one (41) interviews were conducted in the pursuit of understanding the nature of resistance or adoption. The industry was divided into two areas of study: horsemanship and hoof care. Within these areas, the industry was now divided into the two opposing opinions of natural and traditional. The four factions provide an opportunity to view the industry that is equally weighted on all sides. The interviewees represent leaders in the following areas of the equine industry (see Table 1).

The interviewees represent 4 countries, and 17 U.S. states (see Table 2). With over 1,800 minutes of text, the interview process ranges between 25 minutes to 77 minutes. Most interviews were conducted in person, although the international interviews and some U.S. interviews were conducted over the phone.

There is a minimum of ten participants in each faction: Natural Horsemanship (NHP), Natural Hoof Care (NHC), Traditional Horsemanship (THP),

Table 1. Industry Interviewee List

\begin{tabular}{|l|}
\hline \multicolumn{1}{|c|}{ Area of Expertise } \\
\hline Hall of Fame Farriers and Traditional Farriers \\
\hline Amish Horseman and Tradesman \\
\hline Natural Horsemanship Leaders, Trainers, and Licensed Instructors \\
\hline American Farrier Association Leaders \\
\hline Farrier School Owners and Operators \\
\hline Equine Podiatry Leaders and School Founders \\
\hline Veterinarians: Western and Eastern Medicine \\
\hline Racing Industry CEOs, Professionals and Industry Leaders \\
\hline Alternative Equine Therapy Leaders \\
\hline Directors of Equine Rescues \\
\hline Traditional Iconic Trainers \\
\hline Grand Prix 5-star Dressage Riders \\
\hline Therapeutic Riding Center Directors \\
\hline National Champion USEF Combined Driving \\
\hline Collegiate Equine Competitive Team Captain \\
\hline Three Day Event Riders \\
\hline CEOs of Equine Medical Companies \\
\hline International Barefoot Trimmers in the Racing Industry \\
\hline Iconic Company Founders in both Natural and Traditional Horsemanship \\
\hline Kentucky Derby Winner 3rd Generation Horseman \\
\hline Saddle and Equine Tack Manufacturers \\
\hline Equine Body Workers \\
\hline Olympic Level Jumping Horse Trainers and Competitors \\
\hline Equine Natural Trimmers Who Are in Leadership Roles \\
\hline Thoroughbred Breeders for Racing Industry \\
\hline
\end{tabular}




\section{Methodology}

Once the data was gathered, the coding process began with hand coding of each interview. This data was also coded into the NVivo software version 12.0. I chose to use NVivo as a sorting software to replace hand sorting of important information into categories (NVivo-Nodes). NVivo can play a powerful role in coding data and addresses validity threats (Siccama \& Penna, 2008). Memos were then created for each interview or case from the initial hand-coded transcripts. The NVivo software is designed to compare word, text, and relationship entities of the data coded into each node. The hand coding allowed for easier memo writing, as well as creating an ongoing list of theme ideas for analysis. Quotes, repetitive phrases or ideas, and unique phrasing were also compiled in NVivo as separate nodes. One must remember that although NVivo has great potential for sorting information, it does not replace researchers for data interpretation. Researchers will still need to set aside time to read, synthesize, and draw inferences from NVivo sorted data (Auld et al., 2007).

An alphabetized code book of 64 parent codes and 10 child codes was created in NVivo to capture the transcript data. The highlighted codes in Table 4 are of interest in researching industry beliefs. Comparison of Natural versus Traditional groups was completed to analyze the differences among them. Relationship analysis was conduct- ed at the code and axial level. All codes are valid in the initial stage of line by line coding.

According to a published paper by Boeije (2002) entitled "A Purposeful Approach to the Constant Comparative Method in the Analysis of Qualitative Interviews," there were five steps revealed for comparison:

1. Comparison with a single interview

2. Comparison between interviews within the same group

3. Comparison of interviews from different groups

4. Comparison in pairs at the level of the couple

5. Comparing couples

This type of analysis will provide the framework for my research. Comparing traditional and natural beliefs is a sound model for determining the patterns exposing thematic codes. Memos created for each interviewee may also provide additional direction for creating more general themes through axial coding methods.

The analysis process is important to the findings. There are several objectives that must be addressed to complete the research as outlined. To project a tipping point hypothesis, the data was coded into long-standing belief systems for each faction. The factions are: Natural Hoof Care (NHC), Natural Horsemanship (NHP), Traditional Hoof Care (THC), and Traditional Horsemanship (THP). With respect to the research question at hand, the purpose of the protocol is to identify reasons as to why peo

Table 4. NVivo Code Book

\begin{tabular}{|l|l|}
\hline \multicolumn{1}{|c|}{ Parent Code (Node) } & \\
\hline Adopter of Change & \\
\hline Being a First-Generation Horseman & \\
\hline & No \\
\hline Growing up on a ranch & Yes, Family Lineage \\
\hline How long in the NHC Industry & \\
\hline How long in the THC Industry & \\
\hline How long in the NHP Industry & \\
\hline How long in the THP Industry & \\
\hline NHC Beliefs LSBS & \\
\hline NHP Beliefs LSBS & \\
\hline Resistor of Change & \\
\hline Respecting Family & \\
\hline THC Beliefs LSBS & \\
\hline THP Beliefs LSBS & \\
\hline
\end{tabular}


ple adopt or resist change. An executive decision was made to focus solely on the long-standing belief systems as they are the main priority for my research. Figure 1 is a representation of the coding process.

Within the long-standing belief system codes (the assumption that an elicited response such as adoption or resistance to the proposed phenomenon of the natural horse movement) it made sense to isolate the traditional viewpoints. It is my belief that the adopters are not the focal point for this research quest. They are already in agreement with adoption. The shift has been made. Research has provided data to support the findings that within the traditional faction are members who are total resisters of any new beliefs and wish to remain with the status quo, as well as members who are traditional resisters but show tendencies to adopt new beliefs. Within this section, we inquire as to who are the resisters, and what traits or beliefs do they have in common? Who are the resister/adopter hybrids that are making the subtle shift towards possible tipping? The following section is dedicated to showing evidence that supports the process flow in identifying why change . An executive decision was made to focus solely on the long-standing belief systems as they are the main priority for my research. Figure 1 is a representation of the coding process.
Within the long-standing belief system codes (the assumption that an elicited response such as adoption or resistance to the proposed phenomenon of the natural horse movement) it made sense to isolate the traditional viewpoints. It is my belief that the adopters are not the focal point for this research quest. They are already in agreement with adoption. The shift has been made. Research has provided data to support the findings that within the traditional faction are members who are total resisters of any new beliefs and wish to remain with the status quo, as well as members who are traditional resisters but show tendencies to adopt new beliefs. Within this section, we inquire as to who are the resisters, and what traits or beliefs do they have in common? Who are the resister/adopter hybrids that are making the subtle shift towards possible tipping? The following section is dedicated to showing evidence that supports the process flow in identifying why change might be happening to long-standing belief systems. It is important to reiterate that the equine industry is made up of beliefs that have points of origin that existed prior to the holder's experience. Therefore, the change may be subtle and slow, but evident in the qualitative findings. The coding process and synthesis of interview transcripts are illustrated in Figure 2. This data is outlined and discussed at length in the findings section of this document.

\section{Figure 1. Long-standing Belief System Comparison Process}

\begin{tabular}{|c|c|}
\hline \multicolumn{2}{|c|}{ Transcripts $1-41$} \\
\hline Hand Coded & NVivo Coded \\
\hline \multicolumn{2}{|c|}{ Long Standing Belief Systems } \\
\hline Traditional & Natural \\
\hline \multicolumn{2}{|c|}{ Categories } \\
\hline Patterns & Top Responses $>7$ \\
\hline \multicolumn{2}{|c|}{ Break out each Top Response by Identifier (EX: THC 1) } \\
\hline Traditional -Adopters & Traditonal - Resisters \\
\hline \multicolumn{2}{|c|}{ Master Spreadsheet for Identifiers } \\
\hline First Generation & Code Response \\
\hline \multicolumn{2}{|c|}{ Reference Memos per Identifier } \\
\hline Open Code & Secondary Coding CAT \\
\hline \multicolumn{2}{|c|}{ Axial Code } \\
\hline Compare Adopters and Resisters Identified & Possible reasons for adopting or resisting \\
\hline
\end{tabular}




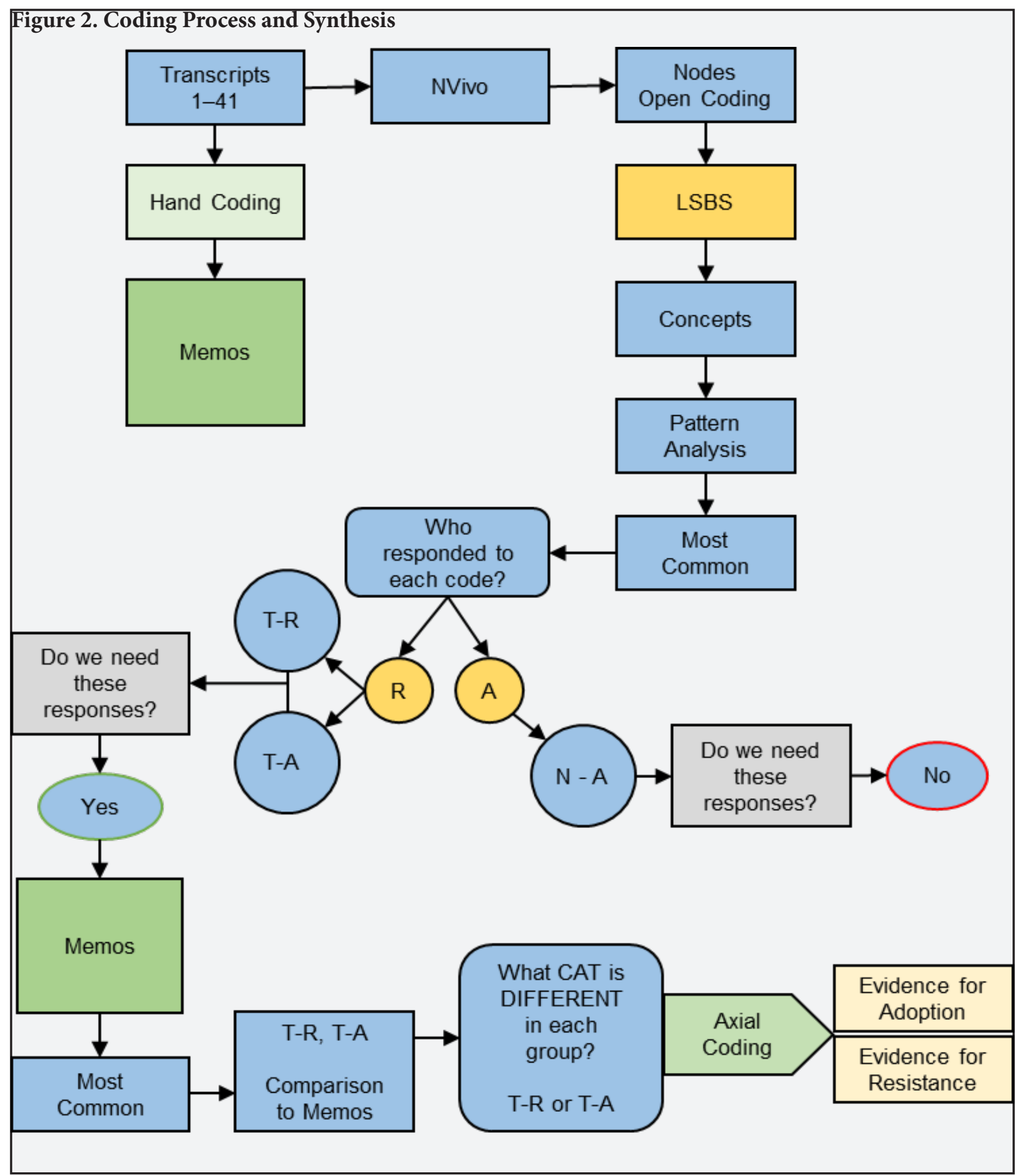

and Tradition Hoof Care (THC). There are 11 participants in the THP division to equal a total of 41 interviews conducted. At least five of each members of the division are top industry leaders, pushing the change, acting in an adopter or resister capacity. No more than five members in each division are acting as a professional leader in middle management in the industry (e.g., professional trimmers, veterinarians, or farriers). Middle management professionals are defined as industry leaders that are practicing in the traditional or natural faction, acting as industry role models, but not the actual innovators of a new science or belief system, such as a veterinarian or breeder. While many of our participants are the founders of a new belief system such as natural horsemanship, many are professionals that are witnessing the opposing forces and having to manage the friction daily. 
Table 2. Interviewee Residence

\begin{tabular}{|l|l|l|}
\hline \multicolumn{1}{|c|}{$\begin{array}{c}\text { State, Town, or } \\
\text { City }\end{array}$} & \multicolumn{1}{|c|}{$\begin{array}{c}\text { Number of } \\
\text { Participants }\end{array}$} \\
\hline Florida & USA & 21 \\
\hline Colorado & USA & 4 \\
\hline Georgia & USA & 2 \\
\hline Texas & USA & 2 \\
\hline Missouri & USA & 1 \\
\hline Massachusetts & USA & 1 \\
\hline Minnesota & USA & 1 \\
\hline Iowa & USA & 1 \\
\hline Illinois & USA & 1 \\
\hline Alabama & USA & 1 \\
\hline New York & USA & 1 \\
\hline Virginia & USA & 1 \\
\hline Kent & UK/Ireland & 1 \\
\hline Cheshire & UK & 1 \\
\hline Paris & France & 1 \\
\hline Calgary & Canada & 1 \\
\hline
\end{tabular}

\section{The Interview}

The interview process was started on January 24, 2018, in Ohio, and finalized on May 13, 2018 via the last phone interview with a participant in Florida. All participants were advised of the anonymity and purpose of this research through a signed "informed consent form." All participants were interviewed using a semi-structured format, with the same set of questions. The questions contain two areas of interest: history and industry. Within the history section, participants were asked about job descriptions, typical daily experiences, family lineage, early equine experiences, and what they know to be true about horses. Within the industry section, questions centered on their expert opinions about natural versus traditional in the hoof care and horsemanship areas. Interviewees were encouraged to expand on equine experiences in order to tap into their long-standing beliefs without actually asking them the specifics of what they believe. Participants were asked about business goals, industry goals, and industry trends (see Table 3).

The interviewees disclosed colorful stories of youthful memories of horsemanship, showing and hoof care experiences. Many interviewees were found through a professional connection, and many were referred by other interviewees. All interviewees saw the value of this study to further the knowledge base of the equine industry. To my knowledge,
Table 3. Qualitative Interview Inquiry Topics

\begin{tabular}{|l|l|}
\hline Equine & $\begin{array}{l}\text { Interview Questions on Long-stand- } \\
\text { ing Belief Systems }\end{array}$ \\
\hline History & Equine job description \\
\hline & $\begin{array}{l}\text { Early equine experience. Are you a } \\
\text { first-generation horseman? Family } \\
\text { lineage. }\end{array}$ \\
\hline & $\begin{array}{l}\text { How many horses do you currently } \\
\text { own? }\end{array}$ \\
\hline & $\begin{array}{l}\text { What has prepared you for this path } \\
\text { in life? }\end{array}$ \\
\hline & Recreational or show riding \\
\hline & $\begin{array}{l}\text { What do you know to be true about } \\
\text { horses? Horses are always }\end{array}$ \\
\hline & $\begin{array}{l}\text { Strengths and weaknesses of working } \\
\text { with horses }\end{array}$ \\
\hline & Advice for newcomers \\
\hline Industry & $\begin{array}{l}\text { How do you describe Traditional and } \\
\text { Natural Hoof Care? }\end{array}$ \\
\hline & $\begin{array}{l}\text { Strengths and weaknesses of Natural } \\
\text { and Traditional Hoof Care }\end{array}$ \\
\hline & $\begin{array}{l}\text { Industry trends for either Traditional } \\
\text { or Natural Hoof Care }\end{array}$ \\
\hline & $\begin{array}{l}\text { How do you describe Traditional and } \\
\text { Natural Horsemanship? } \\
\text { whole }\end{array}$ \\
\hline $\begin{array}{l}\text { Strengths and weaknesses of Natural } \\
\text { ond Traditional Horsemanship } \\
\text { or Natural Horsemanship }\end{array}$ \\
\hline $\begin{array}{l}\text { Innovation and mentors. Research } \\
\text { avenues }\end{array}$ \\
\hline Challenges in the industry \\
\hline & \begin{tabular}{l} 
Goals for your business in the future \\
\hline
\end{tabular} \\
\hline &
\end{tabular}

no such study has been performed in the aspect of long-standing belief systems of adoption and resistance within this industry. Historically, this could benefit the business aspect of the industry as well as further the understanding of the opinions of industry leaders of the four leading factions: Natural Horsemanship (NHP), Natural Hoof Care (NHC), Traditional Horsemanship (THP), and Traditional Hoof Care (THC). 


\section{Findings}

Initially, it was determined from the traditional faction data (21 traditional members), that there are twelve resisters and nine adopters that contradict the traditional belief system on some level. More concretely, the adopters are those who demonstrate some form of natural or new thinking, even though they identify as traditional members.

Individuals were classified as resisters based on criteria that included one or more statements indicating lack of receptivity to considering alternative perspectives. Excerpts from those who were classified as traditional resisters are as follows:

- I am a true believer of the old-fashioned way. It's worked for years and I don't see where it would not continue to work.

- I just know from the general culture that horses had shoes, but I didn't think much of it at the time. I think people that have shod horses stick to what they do and what they know and to their farriers. I think there is something very special to the farrier industry that is ingrained in tradition.

- I basically keep my horses the way I've kept them all my life. It's the way I do it.

- It's the way it's always been done. This is the way we're going to do it, and it works, so we're going to do it this way. I think sometimes people who are more traditional really don't care about the horses much, but rather what the horse can produce for them.

- I wanted to call it traditional [horsemanship], okay, that's not a bad word. It can be good horsemanship. Tradition doesn't have to be bad. That's what's happening is everyone is placing traditional horsemanship on the category of bad because it's traditional.

- There was all old-time horseman, that everything they knew, they knew from experience.

- I was brought up with the old, traditional, great trainers back in my day that were good horsemen. And if they're good horsemen and treat your horse right, you'll get the same results or better, I find.

It was also determined that within the natural faction data (20 Natural Members), there were 20 adopters and zero resisters as they had already adopted the new belief system. This finding seemed obvious given the nature of alternate horsemanship beliefs.

Individuals were classified as adopters based on criteria that included one or more statements indicating acceptance of alternative perspectives. Excerpts from those who were classified as a natural adopter are as follows. Coding provided the categories such as apathy, family, communication, welfare, and empathy. The importance of these and other categories will be discussed later in the research.
- I am actually going and taking the shoes off my horses, me just physically having to go and do it because and say, okay try it. Breaking the tradition, shifting the paradigm. Make that shift. I mean, horses in the wild, they're not shod, and they're just fine.

- To be honest, I don't really associate with traditional farriers. I never could because of the philosophies are so opposing, what the sense of having a friend you're going to be arguing with all the time?

- We just started looking for alternatives, because I needed to do something. I needed to protect my child. And that's when we found Parelli Natural Horsemanship.

- The non-traditional [natural] is all about communication and partnership and it's recognizing that the horse is an individual and that horse has thoughts of its own and it needs to be respected as such.

- I'd like to say I don't think we disrupted it but we certainly stirred things up with natural horsemanship. Because we started making people question why we beat horses.

- I think more people in the horse industry should approach it from a more thoughtful perspective, which I think is what natural horsemanship does. It teaches you to think about your horse, and what they're experiencing, and how you can change how you interact with them.

- So, every day, I'm challenged with being able to come to her [My horse] with this idea of sharing ideas and thoughts in conversations that start with how we can do this versus that is what I want to do today?

This research should support the patterns that exist within the natural faction. What is it about them that may reveal a reason for adopting new beliefs? The research should also provide patterns that exist within the traditional faction for the nine adopters who are professional leaders within the industry and have begun the process of changing their long-standing belief systems. What is it about those interviewees that allowed this mindset to occur?

An important initial finding post coding involved ascertaining who among the interviewees was a first-generation horseman. In the traditional faction (21 total members), there were 10 first generation horsemen and 11 who had equine family lineage going back two or three generations. In the natural faction (20 total members), there were 13 first generation horsemen and 7 who had a family lineage going back two or three generations. The primary importance of their early exposure revealed where the belief system originated, usually through familial belief systems as described in the interview process. 


\section{Faction Findings}

Table 5 is a record of the responses recorded from coded the NVivo nodes for Traditional Hoof Care (THC) Long-Standing Belief Systems and Traditional Horsemanship (THP) Long-Standing Belief Systems. The top Traditional Hoof Care belief, representing $54 \%$ of the total responses in that node, was that when wear exceeds growth, a horse must wear a shoe. Out of 39 responders, this response was recorded 21 times, or $54 \%$ of the time. This node was populated by coding each individual interviewee's response to the interview questions. The 39 responders were a mixture of natural and traditional experts. The Code Patterns were used to create the secondary Concept Codes which were then used to create the Categories. These categories will be utilized in the next phase of the analysis.

Each traditional section was ranked in descending order of repetition. The higher the repetition, the more weight the concept and category will hold in determining the final factors for adoption or resistance. The next step involved analyzing how each Code was formed by providing making further investigations of the responders themselves. Remember, we need to find out why people in this industry are resisting or adopting the new natural belief system.

The analysis process begins with looking specifically at the traditional concepts of interest. Throughout the interview process, the subjects were referencing their expert viewpoints. The Traditional Hoof Care responses were concerned with protection, the gov- erning principles and time-tested beliefs. They believe all performance or working horses need shoes. Within the Traditional Horsemanship responses, the areas of harsh treatment, value, and safety were most recorded. They took the time to profess how prideful they were of the traditional training and work.

In contrast, the Natural Hoof Care code was recorded as referencing such areas as Adopters or those who support natural hoof care as positive. They believe that the barefoot trend is increasing. The Natural Horsemanship responses heavily involved interacting with the horse and working with the psyche, safety issues, and mindfulness. They also believe that natural horsemanship trend is increasing.

The same process was repeated for the natural sections. Table 6 represents the top codes found in the qualitative process of open coding. It was important to apply a value to the patterns present. The top code represented in the Natural Hoof Care faction is "positive barefoot, shoeless attributes" with 18 responses recorded from 36 interviewees.

\section{Further Traditional Faction Analysis}

The second phase of the coding process took the data from Tables 5 and 6 to provide the framework for the following analysis. The purpose of this phase of analysis was to provide the evidence for analysis regarding the responses of those who adopted (T-A) or resisted (T-R). The classification of adoption or resistance was decided at the NVivo coding stage. Traditional responders were classified within the found categories to demonstrate and articulate the

Table 5. THC, THP

\begin{tabular}{|c|c|c|c|c|}
\hline Categories & Concepts & THC Code Patterns & $\mathbf{R}$ & 39 \\
\hline Welfare & Protection & Wear exceeds Growth $=$ Shoe & 21 & $54 \%$ \\
\hline Closed Mindedness & Governing Principle & Trad - All Horses are Shod & 17 & $44 \%$ \\
\hline Status Quo & Time Tested & It's always worked, why change & 13 & $33 \%$ \\
\hline Limitations & Domestication & Performance $=$ Shoes, Discipline & 13 & $33 \%$ \\
\hline Dependency & Euphanistic & No hoof, no horse & 10 & $26 \%$ \\
\hline Conformity & Existing Conditions & Hoof anatomy rules, shape, angles & 9 & $23 \%$ \\
\hline Personal Development & Pride of Place & Pride in Industry, Good Farriers & 8 & $21 \%$ \\
\hline Economic & Standards & 6-12 week trim cycles & 7 & $18 \%$ \\
\hline Legislation & Regulations & TB Racing, Yearling rules, Track Protocol & 7 & $18 \%$ \\
\hline Categories & Concepts & THP Code Patterns & $\mathbf{R}$ & 37 \\
\hline Welfare & Harsh Treatment & Trad - More Aggressive, Forceful & 33 & $89 \%$ \\
\hline Economy & Value & Horse, means to an end, $\$ \$$, Vehicle, Property & 15 & $41 \%$ \\
\hline Protection & Safety & Start horses too early, yearlings under saddle, training & 15 & $41 \%$ \\
\hline Personal Dev. & Pride of Place & Trainers treat horses right, Good trainers, Groundwork & 14 & $38 \%$ \\
\hline Status Quo & Time Tested & It's always worked, why change & 12 & $32 \%$ \\
\hline Power Dynamic & Class Status & Horses need work, ( A job) & 9 & $24 \%$ \\
\hline Control & Submission & Trad - Horses are broke, Broken & 7 & $19 \%$ \\
\hline Communication & Relationship & Trad - Listen to horses, feel them, read them & 7 & $19 \%$ \\
\hline
\end{tabular}


Table 6. NHC, NHP

\begin{tabular}{|c|c|c|c|c|}
\hline Categories & Concepts & NHC Code Patterns & $\mathbf{R}$ & 36 \\
\hline Acceptance & Adopter & Nat - Barefoot, Shoeless, Good for horses & 18 & $50 \%$ \\
\hline Validation & Affirmation & Nat - Nature - Born Wild, Shoeless, God made & 11 & $31 \%$ \\
\hline Compromise & Last Resort & Would be barefoot, unless nec. & 11 & $31 \%$ \\
\hline Strategy & Market Trends & Trend - Nat. Barefoot increasing & 10 & $28 \%$ \\
\hline Pro-Active & Protocol & Nat. - Better care, Care more for foot & 10 & $28 \%$ \\
\hline Open mindedness & Alternatives & "Some" horses can go barefoot, some not & 9 & $25 \%$ \\
\hline Protection & Safety & Boots, Alternative protection, innovation & 7 & $19 \%$ \\
\hline Self Preservation & Conflict & Aggression - Barefoot, natural, friction & 7 & $19 \%$ \\
\hline Enlightenment & Education & "Adopters" - education nec. For horses & 7 & $19 \%$ \\
\hline Categories & Concepts & NHP Code Patterns & $\mathbf{R}$ & 40 \\
\hline Psychology & Interaction & Keep mind busy, Games, Psyche, Brainwork, Childlike & 32 & $80 \%$ \\
\hline Protection & Safety & Not a fan NHP, disasterous, dangerous, get hurt & 19 & $48 \%$ \\
\hline Mindfulness & Awareness & NHP -mindfulness, stress free, be a better leader & 18 & $45 \%$ \\
\hline Trustfulness & Priority & NHP - Less forceful, Horse first, gentle training & 17 & $43 \%$ \\
\hline Market Share & Success & Trend - Nat. Horsemanship increasing & 16 & $40 \%$ \\
\hline Welfare & Better Care & More concerned with well-being of horse & 16 & $40 \%$ \\
\hline Patience & Steps to Action & Takes longer, it's a process a journey & 15 & $38 \%$ \\
\hline Competition & Niche Division & Trend - Nat. Horsemanship decreasing & 14 & $35 \%$ \\
\hline Role Modelling & Desired results & Parelli, Natural horsemanship, good for horses & 12 & $30 \%$ \\
\hline Sense of Family & Partnership & Horses are now children, companion animals & 7 & $18 \%$ \\
\hline Social Norms & Question Tradition & Frustrated more people don't see NAT as non abusive & 7 & $18 \%$ \\
\hline
\end{tabular}

factors which led to someone adopting the Natural Belief System, despite being a tried and true traditionalist within the industry, and those which led to resistance. This research aided in articulating the following question: is there a time or belief that may occur that could indicate a shift towards adoption?

One of the unexpected findings of this research was the evidence of a "hybrid" member. The hybrid traditional members were of as much interest as the members resisted the thought of natural horsemanship in any form quite vehemently. Their beliefs that were registered in the adoption column were quite surprising and very important to this research. This pivotal moment in the research shifted my focus from studying those who are already adopters within in the industry (Natural Horsemanship and Natural Hoof Care) to a laser focus on those who were true Traditional members. What about them identified them as $100 \%$ traditional and resisting the phenomenon of a new belief system within the stagnant industry? What beliefs in some were creating 'hybrids' who considered themselves traditional yet were adopting some natural tendencies and thus changing their long-standing belief systems, sometimes unbeknownst to themselves? This became a new area of study, a deeper focus on the 'hybrid' section.

The traditional responses were of as much importance to this process as the natural adopters who had already $100 \%$ bought into the process and some of whom even occupied leadership roles in the industry. The adopters were not important to capture within each faction. What was important was the phenomenon that this research included traditional industry experts acting as leaders and role models for the traditional viewpoint but showed signs of possibly adopting the natural belief by adopting some alternate form of the new belief system. An example of this is taken from a Traditional Adopter (TA) member who is traditional but is now adopting the new belief system.

- We have to try to see if he's going to get better. So, I think you should not use the shoe unless it's absolutely necessary.

- The natural horsemanship people are more readily, I mean clean their stalls better. They think about the bit is pretty dirty, why don't we just clean it? Why am I sticking this cold bit in this horse's mouth? Some things like that have gotten better with the natural horsemanship, I think.

- You got all the natural horsemanship now and all that. I'm into some of that but not all of it.

- Well, the natural I think is more tuning into the psyche of the horse.

- If you have a horse that comes in with issues, I do more natural horsemanship, and then I develop it into traditional, but I still use hints of natural. 
The Third Phase of the Qualitative analysis provided data corresponding to the correlation of memo analysis and NVivo elevated coding. The result was a cross-reference analysis providing a clear picture of the traits which are present amongst the Traditional Resisters and the Traditional Adopters within the Hoof Care and Horsemanship factions. Memo analysis is predominantly important within the proposed Grounded Theory Model which is the direction of this research. Responses from the memo qualitative analysis is important to develop a trait history of each responder. The elevated coding and memo analysis were invaluable in the process of determining the meaning of the 'hybrid' identifier, its purpose and meaning within the research proposed question. Responses of the Traditional members are demonstrated below.

- I am a true believer of Old Fashion ways. It's worked for years and I don't see where it would not continue to work.

- True horsemen are gone.

- They [HORSES] are smart. They understand us. We don't always understand them.

Memo response for this traditional resister: Status Quo, Could never live without a horse, selfless, caring, empathetic, "if it ain't broke, don't fix it", likes horses more than people at times, values people who volunteer.

We didn't look at the customer base. To understand the customer base would look at that label of natural, organic, barefoot, whatever they call it. So unfortunately, I think if traditional guys would've marketed themselves as a barefoot trimmer, then we could've gotten ahead of it, but it ended up becoming two camps, almost political or religious, you know?

Memo responses for this traditional resister: Never mentions loving the horse, hard job, respectful of old timers in the industry, highly respects authority, self-motivated, self-starter, humble to the industry, not ego driven, status quo important, family and family time extremely important, "if it ain't broke, don't fix it."

- I'm not worried about internal of the horse, and what the butt is doing, and the neck is doing. I'm worried about the legs and feet.

- I said this to a group of people, and they liked $i$ t, a vet a [n] [EQUINE] chiropractor and a trainer walk into a bar, and the farrier gets fired.

Memo responses for this traditional adopter: Believes in reputation, very important, Education is extremely important, perfectionist, disciplined, sees bigger picture, proud, jaded, defensive, passionate about job, good work ethic, loves horses.

The thoroughbred industry, which I'm most associated with, there is an error of exploitation of the horse. So, it's a mean to an end, as opposed to something that you go on a journey together with. In that light, I see a lot of the commercialization of horses, and I don't see and so that's very traditional in a context that's the way it's been done. The race horse is there to be a race horse.

Memo responses for this traditional adopter: Gentle soul, ethical, humble, loves animals, loves horses specifically, researcher, respects experts, family important, leader in industry, concerned with horses' well-being.

\section{Final Faction Findings}

The fourth phase of this qualitative analysis, memo reference and cross-reference protocol provided the grid assigned as figure 3 . The over whelming responses are represented below. Traditional hoof care and horsemanship responses from those who qualify as resisters are shown in the top half of the grid. The bottom half of the grid represent the Traditional hoof care and horsemanship responses from those who qualify as adopters. At this level of coding, the qualitative elevated codes present the traits and characteristics that were the most common within the interview process and memos. The purpose of this grid is to show evidence in traits that may shed light into why some adopt and some resist within the Traditional faction. The original purpose of this study was to determine why people resist or adopt to change. The equine industry proved to be an informative pool for the purpose of this study. Common traits were now evident among the resisters as well as among adopters. Through the category classification, this research was able to deduce several assumptions in the grounded theory goal regarding adoption and resistance within long-standing belief systems.

\section{Discussion}

Within the context of this research, the concern is focused on the concepts or traits that are exhibited with those who resist versus those who adopt. By using the traditional faction only in the axial stage, the results are more likely to display the existence of a possible tipping point as stated in Lewin's (1997) theory, Force Field Analysis. This theory describes the characteristics or traits people display that, once weighted, could possibly indicate signs of adoption or tipping. 
Figure 3. Traditional-Resister, Traditional-Adopter: Traditional Hoof Care (THC), Traditional Horsemanship (THP) Comparison Grid

\begin{tabular}{l}
$\quad$ THC T-R \\
\hline Traditonal Cowboy \\
Hall of Famer \\
Nature/God \\
Resisting Natural \\
Professional Relationships Prob. \\
Innovator \\
People Person \\
Resonsible/trustworthy
\end{tabular}

\section{THC T-A}

Jaded

Open-minded

\section{vulnerable}

The Traditional Hoof Care (T-R) area of the grid in Figure 3 is important as it demonstrates that Traditional members of the THC who adamantly resist the new belief system [natural] are traditional cowboys. The resisters referenced being on the rodeo circuit and/or practicing western cowboy-themed disciplines. These members displayed pride for their "hall of fame" status as farriers. They considered farriers family. They actively spoke about resisting nature and were aware of certain problems with professional relationships, be it Vet/Farrier, Farrier/Client, or Farrier/Farrier. They mentioned innovative areas within the industry such as new shoe techniques or products. They talked about the importance of being kind to clients, and educating one another. Finally, they discussed the importance of being responsible, hardworking, and trustworthy. These are just a few excerpts from the transcripts to support the findings.

- Any parent always wants their child to have something better than they do, so it's about bettering our family. It's about bettering our industry. You want it to evolve. It can only get better. If we are only teaching people to be at the level you're at then there's no growth in

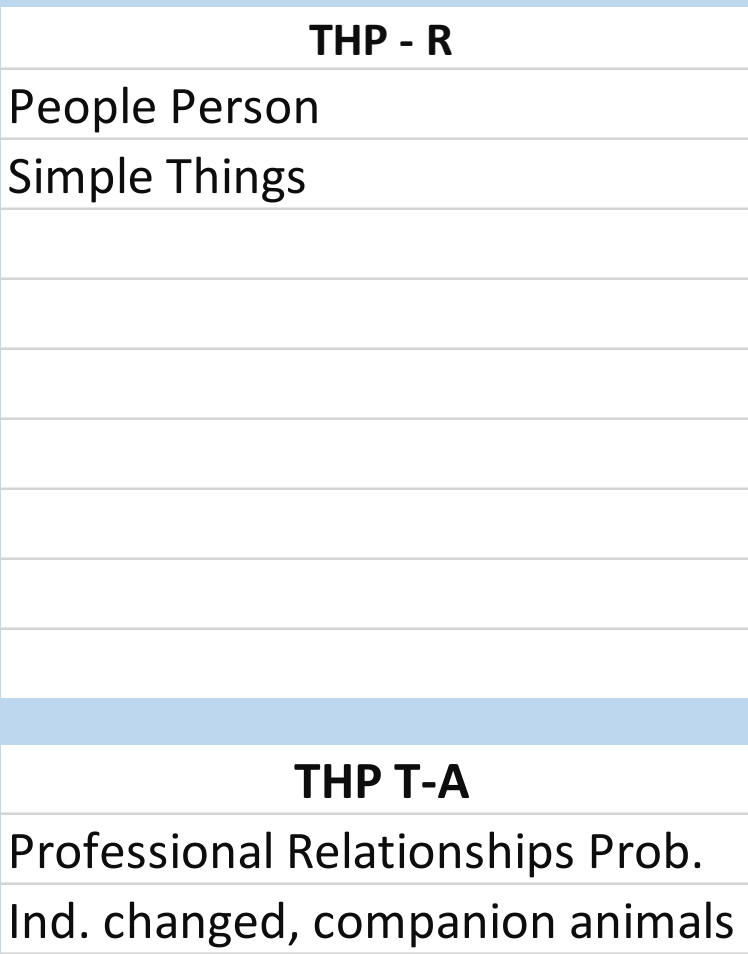

Fixer

Jaded

the industry. This should be an ever-evolving situation.

- In my mind, there's five things you've got to have to be a good farrier. You must be great on the horse, the horsemanship. You've got to be great with your trimming skills, so all your hoof prep. You've got to be great in the forge. But the other two are you got to be a great businessman, businessperson, and you have to have good people skills.

- I think it's important to really trust the farrier because I know a bad trim job, or a bad shoeing can cause a lot of problems. I mean the farrier I had, I had known him before I ever owned a horse, and I trusted him, so I would go to him with all my hoof questions since he approached it the same way, I did, with the same concepts.

- Man, "them old cowboys" when I was growing up, they used to tell me, they'd say, don't be doing that. I rode broncs, rode bulls, all this kind of stuff. Don't be doing that. You know them colts getting in a wreck. Don't be stupid. [I'd say] he's just a stupid old cowboy, what does he know. Now I know what he knew. 
- Less is better I think, because you know, God made them a certain way, and you start messing with that and then you're asking for it.

Common attributes amongst the Traditional Hoof Care Resister Group (T-R) include being proud, responsible, traditional cowboys who value the way things have been done for years. They are open-minded about innovation within their industry, but actively resist anything to do with natural horsemanship. Many are members of the elite group of farriers, considered Hall of Famers by the American Farrier's Association. They are role models and believe that nature and God have created the foot to be perfect. Man's dedication to higher disciplines requires further application of the horseshoe. The welfare of the horse is extremely important, and by shoeing the horse, they believe they are protecting it from harm or pain.

In addition to Traditional Hoof Care Resisters, there are also Traditional Horsemanship Resisters. These members are traditional horsemanship members that also adamantly resist any new belief system [natural]. They asserted that people are important to the business. Many discussed being in service industries such as therapeutic riding centers where volunteers are important and valued, and clients with disabilities are a top priority. Many discuss the busy nature of the business, having to tend to horses $24 / 7$ and are looking forward to retiring and getting back to a simple life. They valued the simple things as important.

- I don't care if the horses we keep racing ever even run as a two-year-old. It's not important to be a runner, and it's not important to shove one and make it make the Kentucky Derby on the first Saturday in May. I don't care.

- I like the old stuff, going back and eliminating the vet care if you can by using the old-time remedies, which have been around forever. They are, a lot of the herbs and stuff like that.

- A lot of people will come and want to get into the horses. They've always wanted to do that and never had the opportunity. And we get some very good volunteers that way, and they get very horse knowledgeable.

- I think it has to do a lot with courage because again, I did what I did. I went through financial struggle which most people aren't willing to do. The Traditional Hoof Care, Adopters (T-A) area of the grid in Figure 8 is important as it demonstrates that the Traditional members of the THC who are adopters at some level of the new belief system [natural] could be described as jaded, open-minded and vulnerable. From the research, it was recorded that many traditional members of the THC adopted the belief that natural horsemanship has a place in their business. They exhibited areas of vulnerability in their responses and a possible jaded expression towards the traditional members. The areas of vulnerability may allow for more adoption to happen. Being frustrated and jaded may be precursors to adopting as well.

- So, they just look at it from a physical aspect, as if the horse were a piece of machinery.

- When I see a good idea, I latch onto it and I use it, because there's value in everything.

- The funny thing is, a lot of farriers have a big ego, simply because it's the way of the business.

- No matter how good you do, unless you follow them, then you're going to fail because the first track farrier is going to all this BS to them and they just go downhill from there.

In correspondence to the grid, the next areas of adopters were in the Traditional Horsemanship Adopters (T-A) section. These members are traditional horsemanship members that demonstrate adoption on some level of the new belief system [natural]. They actively are aware that there is a problem between professional relationships, be it Vet/ Farrier, Farrier/Client, or Farrier/Farrier. They want these relationships to be better for the sake of the industry. They also see a change in the industry in that horses are now companion animals. An interesting attribute that came to light is that there was a characteristic of wanting to "fix" horses, or people. Another interesting attribute was also being jaded towards the industry with people or horses.

- If you think about the traditional world, it is very much ruled by trainers. And people who had a lot of knowledge that would train your horses and then teach you and usually wouldn't share their secrets with you, right? So, there was always this job security and authority, because I know, and you don't know.

- Everything we do in this business is about money.

- We heard a very well-known clinician at a recent horse event saying that you can never miss a day of training. And we just looked at each other and went, wow, that's sad.

- Horsemanship is horsemanship. I don't care what you call it.

- Like great heroes and watching them run and develop these superstars. Our industry, it's a 
good thing and a bad thing at the same time. There's no doubt that affects things.

The commonality of the T-R Traditional Hoof Care and Traditional Horsemanship groups included the awareness of people as their client, the importance of respect from their clients, and the responsibility to be trustworthy participants within the industry. People who value other people's involvement in their industry also value communication. A people person is someone who is outspoken and does not hesitate to speak his mind or speak up for his beliefs. Many responders spoke up for the resisting of natural horsemanship and fear that the traditional horseman or cowboy was a dying breed.

The commonality of the T-A Traditional Hoof Care and Traditional Horsemanship groups is to be found in the jadedness of their responses. Jaded responses entail apathy, boredom, or being tired of something. Most members called for a higher standard for students, clients, or colleagues, and expressed frustration with the lack of interest in making positive changes or were tired of seeing the same responses over and over with no effort to change. The adopters no doubt became aware of the apathy towards a certain aspect of the business and that translated to having the motivation to accept change when there had been none in the past.

\section{Conclusions}

The equine industry has meant so many things to so many people, depending on their discipline. However, the core beliefs of this industry have been untouched by change for hundreds of years. The long-standing belief systems embedded within the industry have left the industry as an "us" against the "horse" industry. This impactful belief has created beliefs that belong in the "closed group" of people. Nothing was in question, no one was doing things that were not accepted. The industry is currently in a state of friction where the "us" versus "them" mentality replaced the "us" versus the "horse" viewpoint. Both sides begin to justify why their way of being in the industry is better. There are many reasons as to why people adopted this viewpoint. This research supports the study of why someone either resists or adopts the new belief system [natural] over the status quo [traditional]. Qualitative data was examined and synthesized to determine what characteristics or traits are present in those who adopted and those who resisted. The research viewpoint is to examine the traditional participants who adamantly resist. This research revealed that traditional participants who resisted in the factions of hoof care and horsemanship both referenced people and the value of the client. These participants were outspoken and in most cases role models and leaders to the industry. They value their job and take pride in their interactions. The other viewpoint examined was the traditional participants who adopted showed areas of being jaded and apathetic. These participants had a high standards for themselves and others around them including the horse. Frustration and/or being tired of the industry seemed to be the stepping point for change and adoption to occur. The traditional participants were required to adapt before they adopted the new belief system.

Future research in adoption may be important. The same steps can be taken to analyze and synthesize the data with T-A and T-R to further understand why they did adopt. These experts in the industry exhibit leadership roles that further the education of natural horsemanship. The industry would derive further benefit from taking this study one step further in the future and examining the adopters still more closely.

Future research will also include a grounded theory model in change management. Findings from this study will be used at an axial coded level where themes are formed, and new theory is generated. The future study's purpose will be to elevate the research findings to a macro level of understanding to further the explanation of why people adopt or resist change in a business setting. Characteristics and traits are a valuable tool in the analysis process and will be used to forward the understanding of how a business can successfully promote change within their corporate environment.

\section{References}

Auld, G. W., Diker, A., Bock, M. A., Boushey, C. J., Bruhn, C. M., Cluskey, M., Olson, B. H. (2007). Development of a decision tree to determine appropriateness of NVivo in analyzing qualitative data sets. Journal of nutrition education and behavior, 39(1), 37-47. doi:https://doi.org/10.1016/j. jneb.2006.09.006

Birke, L. (2007). Learning to speak horse": The culture of "Natural Horsemanship. Society and Animals, 15(3), 217-239. doi:10.1163/156853007X217177

Boeije, H. (2002). A purposeful approach to the constant comparative method in the analysis of qualitative interviews. Quality and Quantity, 36(4), 391-409. doi:https://doi. org/10.1023/A:1020909529486 
Bremer, M. (2012). Organizational culture change: Unleash your organization's potential in circles of 10. Kikker Groep, 2012

Gleeson, B. (2017). 1 reason why most change management efforts fail: Forbes Magazine. Retrieved from https://www.forbes.com/sites/brentgleeson/2017/07/25/1-reason-why-most-changemanagement-efforts-fail/\#4b6b81dd546b

Kuhn, T. S. (1962). The structure of scientific revolutions. Chicago, IL: University of Chicago Press.

Lewin, K. (1997). Resolving social conflicts and field theory in social science. American Psychological Association. doi: https://doi.org/10.1037/10269$\underline{000}$

Siccama, C. J., \& Penna, S. (2008). Enhancing validity of a qualitative dissertation research study by using NVivo. Qualitative research journal, 8(2), 91-103. doi:https://doi.org/10.3316/QRJ0802091

Stegaroiu, I., \& Talmaciu, I. (2016). Causes of Resistance to Change. What Managers Should Do? Risk in Contemporary Economy, 133-138.

Usó-Doménech, J., \& Nescolarde-Selva, J. (2016). What are Belief Systems?. Foundations of Science, 21(1), 147-152. doi:https://doi.org/10.1007/ $\underline{\text { s10699-015-9409-Z }}$

\section{Review}

This article was accepted under the constructive peer review option. For futher details, see the descriptions at:

http://mumabusinessreview.org/peer-review-options/

\section{Author}

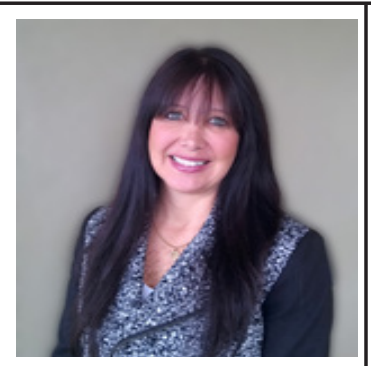

Robyn Lord is the Co-Founder and CEO of the Institute of Applied Equine Podiatry, Inc. in Naples, FL. Lord oversees all business and program development, product development, as well as student recruitment and assessment. Currently, the institute has graduates in over 18 countries. Lord received her BS in Business Administration from Castleton State College in VT (1999) with High Honors, an Executive MBA from Florida Gulf Coast University in FL (2015) and a Doctorate in Business Administration (DBA) from University of South Florida in Tampa (2018). 